\title{
Resection of thyroid carcinoma infiltrating the trachea
}

T. ISHIHARA, K. KIKUCHI, T. IKEDA, H. INOUE, S. FUKAI, K. ITO ${ }^{1}$, AND T. MIMURA ${ }^{1}$

From the Department of Surgery, School of Medicine, Keio University, Tokyo, and Ito Hospital', Tokyo, Japan

Ishihara, T., Kikuchi, K., Ikeda, T., Inoue, H., Fukai, S., Ito, K., and Mimura, T. (1978). Thorax, 33, 378-386. Resection of thyroid carcinoma infiltrating the trachea. We have treated surgically 11 patients with thyroid carcinoma that had infiltrated into the trachea. Three patients had primary tumours, and eight had recurrent tumours after previous operations.

Sleeve resection of the trachea was performed where thyroid carcinoma had proliferated; the trachea was reconstructed by end-to-end anastomosis. In two patients 10 rings of the trachea were resected. In three patients the anterior half of the cricoid cartilage was resected along with the cervical trachea. In one patient tracheoplasty was performed using partial extracorporeal circulation because severe tracheal stenosis prevented endotracheal intubation. Two of the 11 patients died from the surgery and one from disseminated metastases. One patient who had undergone tracheal resection for thyroid carcinoma three years and five months previously had a recurrence of the tumour in the trachea adjacent to the anastomosis, and a second tracheal resection was performed. In three patients postoperative laryngeal stenosis occurred. Five patients are alive and well two years and one month to four years and seven months after their operations.

The histological pattern of the tumour was papillary adenocarcinoma in all 11 patients.

There are only a few reports on the surgical treatment of tracheal infiltration by thyroid carcinoma. In the four-year period covered by our survey in Japan only 44 patients, including our 11 patients, had surgical treatment of tracheal infiltration by thyroid carcinoma.

Tracheal infiltration by thyroid carcinoma causes tracheal stenosis and haemoptysis, which is often fatal. Therefore, surgical treatment of thyroid carcinoma should be performed early to ensure patency of the airway. Many patients with tracheal infiltration by thyroid carcinoma, however, do not present for surgery until large masses have formed in the trachea, so that the ideal conditions are not often met. We describe our surgical methods and the results obtained in patients with tracheal infiltration by thyroid carcinoma.

\section{Patients}

Eleven patients with tracheal infiltration by thyroid carcinoma had surgical treatment in Keio University Hospital between April 1973 and
March 1977. The patients, two men and nine women, ranged in age from 44 to 67 years with an average of 54 years. In 10 of these patients the cervical trachea was affected. In the other patient thyroid carcinoma had infiltrated into the mediastinum as a result of repeated recurrences, ultimately affecting the lower part of the trachea and the right main bronchus.

Eight of the 11 patients had recurrent thyroid carcinoma, and three were primary cases. The of periods from the first operation for thyroid car- $N$ cinoma to development of symptoms of tracheal $N$ infiltration were one year, one year and five months, five years, 22 years, 24 years, and 25 years. In two patients malignant tissue remained in the part of the tracheal wall treated at the first opera- $\stackrel{\oplus}{\rightleftharpoons}$ tion. The time from onset of symptoms of tracheal infiltration to surgical treatment was two months, three months, four months, eight months, nine $\underset{\mathbb{D}}{\mathbb{D}}$ months (two cases), one year and five months, $\frac{\rho}{\Phi}$ one year and 10 months, four years and one $\frac{\varrho}{\sigma}$ month, five years, and five years and six months.

All 11 patients had blood-stained sputum. Five 
Table Summary of data on 11 patients

\begin{tabular}{|c|c|c|c|c|c|c|c|c|}
\hline $\begin{array}{l}\text { Case } \\
\text { No. }\end{array}$ & Age & Sex & $\begin{array}{l}\text { Duration } \\
\text { of thyroid } \\
\text { carcinoma } \\
\text { before } \\
\text { operation }\end{array}$ & $\begin{array}{l}\text { Previous } \\
\text { treatment }\end{array}$ & Operation & $\begin{array}{l}\text { No. of rings } \\
\text { resected }\end{array}$ & Result & $\begin{array}{l}\text { Time since } \\
\text { operation }\end{array}$ \\
\hline 1 & 56 & $\mathbf{F}$ & 6 months & $\begin{array}{l}\text { Subtotal } \\
\text { thyroidectomy. } \\
\text { Radiotherapy }\end{array}$ & $\begin{array}{l}\text { Resection of } \\
\text { affected trachea. } \\
\text { Primary } \\
\text { anastomosis }\end{array}$ & 5 & Alive and well & 4 years 7 months \\
\hline 2 & 61 & $\mathbf{F}$ & $\begin{array}{l}5 \text { years } \\
6 \text { months }\end{array}$ & $\begin{array}{l}\text { Subtotal } \\
\text { thyroidectomy. } \\
\text { 131 I treatment }^{\text {I }}\end{array}$ & $\begin{array}{l}\text { Resection of } \\
\text { affected trachea. } \\
\text { Primary } \\
\text { anastomosis. } \\
\text { Reoperation } \\
3 \text { years } 5 \text { months } \\
\text { later }\end{array}$ & $\begin{array}{l}5 \\
\text { Total } 8\end{array}$ & $\begin{array}{l}\text { Stenosis of } \\
\text { anastomotic site. } \\
\text { Alive without } \\
\text { relapse }\end{array}$ & $\begin{array}{l}1 \text { year } 1 \text { month } \\
\text { after second } \\
\text { operation }\end{array}$ \\
\hline 3 & 44 & $\mathbf{M}$ & $\begin{array}{l}5 \text { years } \\
6 \text { months }\end{array}$ & None & $\begin{array}{l}\text { Subtotal } \\
\text { thyroidectomy. } \\
\text { Sleeve resection } \\
\text { of affected trachea. } \\
\text { End-to-end } \\
\text { anastomosis }\end{array}$ & 7 & Alive and well & 4 years 1 month \\
\hline 4 & 46 & $\mathbf{F}$ & 25 years & Thyroidectomy & $\begin{array}{l}\text { Sleeve resection } \\
\text { of affected trachea. } \\
\text { End-to-end } \\
\text { anastomosis }\end{array}$ & 6 & Alive and well & 3 years 7 months \\
\hline 5 & 55 & $\mathbf{F}$ & 27 years & $\begin{array}{l}\text { Subtotal } \\
\text { thyroidectomy. } \\
\text { Radiotherapy }\end{array}$ & $\begin{array}{l}\text { Right } \\
\text { pneumonectomy } \\
\text { with tracheal } \\
\text { resection }\end{array}$ & 4 & $\begin{array}{l}\text { Died on } \\
\text { 7th postoperative } \\
\text { day }\end{array}$ & \\
\hline 6 & 46 & $\mathbf{F}$ & 25 years & Thyroidectomy & $\begin{array}{l}\text { Sleeve resection } \\
\text { of affected trachea. } \\
\text { End-to-end } \\
\text { anastomosis }\end{array}$ & 6 & $\begin{array}{l}\text { Thyroid carcinoma } \\
\text { recurred on } \\
\text { opposite side. } \\
\text { Trachea was } \\
\text { not invaded. } \\
\text { Alive and well }\end{array}$ & 2 years 4 months \\
\hline 7 & 57 & $\mathbf{F}$ & 5 years & Thyroidectomy & $\begin{array}{l}\text { Sleeve resection } \\
\text { of affected trachea. } \\
\text { End-to-end } \\
\text { anastomosis }\end{array}$ & 6 & Alive and well & 2 years 1 month \\
\hline 8 & 49 & $\mathbf{M}$ & 8 months & None & $\begin{array}{l}\text { Thyroidectomy. } \\
\text { Sleeve resection } \\
\text { of affected trachea } \\
\text { and vessels. } \\
\text { End-to-end } \\
\text { anastomosis and } \\
\text { reconstruction of } \\
\text { vessel by graft }\end{array}$ & 10 & $\begin{array}{l}\text { Died } 4 \text { months } \\
\text { after } 1 \text { st operation, } \\
3 \text { weeks after last } \\
\text { operation }\end{array}$ & \\
\hline 9 & 67 & $\mathbf{F}$ & 7 years & Radiotherapy & $\begin{array}{l}\text { Subtotal } \\
\text { thyroidectomy. } \\
\text { Sleeve resection } \\
\text { of affected trachea. } \\
\text { End-to-end } \\
\text { anastomosis }\end{array}$ & $\begin{array}{l}6 \text { with a part of } \\
\text { cricoid cartilage }\end{array}$ & $\begin{array}{l}\text { Laryngeal } \\
\text { stenosis. } \\
\text { Alive with } \\
\text { pulmonary } \\
\text { metastases }\end{array}$ & 1 year 5 months \\
\hline 10 & 47 & $\mathbf{F}$ & $\begin{array}{l}1 \text { year } \\
10 \text { months }\end{array}$ & $\begin{array}{l}\text { Thyroidectomy. } \\
\text { Chemotherapy }\end{array}$ & $\begin{array}{l}\text { Sleeve resection } \\
\text { of affected trachea. } \\
\text { End-to-end } \\
\text { anastomosis }\end{array}$ & $\begin{array}{l}5 \text { with a part of } \\
\text { cricoid cartilage }\end{array}$ & $\begin{array}{l}\text { Laryngeal } \\
\text { stenosis. } \\
\text { Died of } \\
\text { brain metastases } \\
9 \text { months after } \\
\text { operation }\end{array}$ & \\
\hline 11 & 63 & $\mathbf{M}$ & $\begin{array}{l}1 \text { year } \\
3 \text { months }\end{array}$ & $\begin{array}{l}\text { Thyroidectomy. } \\
\text { Chemotherapy }\end{array}$ & $\begin{array}{l}\text { Sleeve resection } \\
\text { of affected trachea. } \\
\text { End-to-end } \\
\text { anastomosis }\end{array}$ & $\begin{array}{l}10 \text { with a part of } \\
\text { cricoid cartilage }\end{array}$ & $\begin{array}{l}\text { Laryngeal } \\
\text { stenosis. } \\
\text { Alive with } \\
\text { metastases in } \\
\text { cervical vertebra }\end{array}$ & 1 year 8 months \\
\hline
\end{tabular}


had dyspnoea, and in two this was a primary symptom. Six patients had hoarseness, preceding tracheal infiltration in all but one instance.

Tracheal infiltration by thyroid carcinoma was diagnosed by bronchoscopy in six patients, and by tomography of the cervical trachea in five. Before tracheal surgery, three patients were treated by radiotherapy, one by radioisotope, and two by antitumour chemotherapy. These methods, however, were almost ineffective.

In all 11 patients the thyroid tumour was a papillary adenocarcinoma. The Table summarises the data of 11 patients.

\section{Illustrative case reports}

CASE 1

A 56-year-old woman underwent subtotal thyroidectomy and modified left-sided neck dissection in October 1972 for malignant goitre. Since a remnant of the carcinoma was left on the tracheal wall the area was subsequently irradiated with $5000 \mathrm{rad}$ of ${ }^{\circ} \mathrm{Co}$. Two months after the operation the patient came to the hospital complaining of haemoptysis and dyspnoea, and a tracheostomy was performed. Although haemoptysis soon ceased, a tumour in the trachea was observed on the tomogram (Fig. 1) and seen from the tracheal

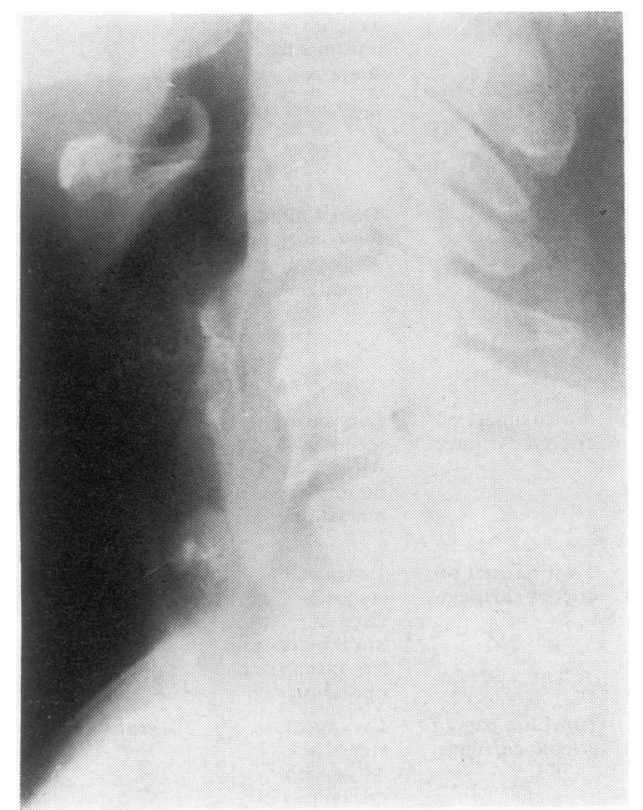

Fig. 1 Lateral radiograph of neck of case 1. A round shadow with calcification is evident in tracheal lumen. stoma. A $2-\mathrm{cm}$ length of the trachea (five rings产 at the site of the lesion was resected, and cone tinuity was restored by primary anastomosis. The patient is now well, four years and seven months after the operation, with no signs of recurrence og the tumour.

\section{CASE 2}

Under the diagnosis of malignant goitre a 61 -yearold woman underwent subtotal thyroidectomy an modified left-sided neck dissection in October 196 The tumour occupied the entire left lobe and was adherent to the trachea, sternothyroid muscle and one of the jugular veins. She was well untid March 1969, when she began to produce blood6o stained sputum, and she then noticed dyspnoeas One year and nine months later radiography showed a tumour projecting into the trachea (Fig2). Treatment with ${ }^{131}$ I was given in May $197 \overline{\mathrm{F}}$ without effect. A bronchoscopy in April 1973. showed a tumour obstructing about three-quarters of the lumen of the cervical trachea. A length of about $1.5 \mathrm{~cm}$ of the trachea (three rings) was ex cised and the defect repaired by primary anastof mosis. In September 1976 hoarseness appeare and haemoptysis recurred. Bronchoscopy showes a recurrence of the tumour on the left wall cranial to the anastomotic site, and brushing of the are

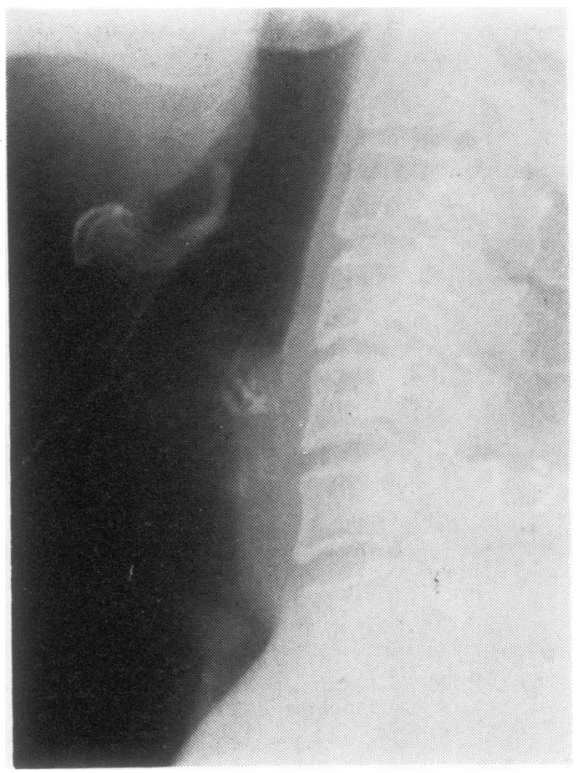

Fig. 2 Lateral radiograph of neck of case 2 taken in December 1970. A tumour projects into lower cervical trachea. 


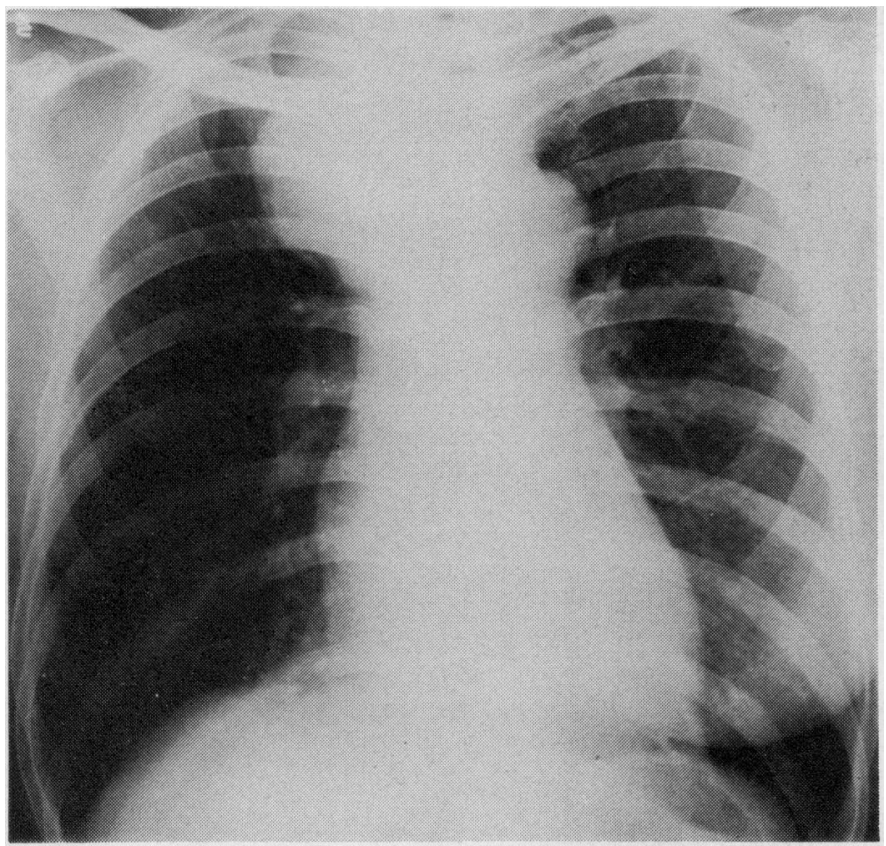

Fig. 3 Chest radiograph of case 5. A large mass in the cervicomediastinal region is evident.

yielded malignant cells. In October 1976 a length of infiltrated trachea including five rings was excised, and laryngeal release was performed simultaneously to reduce the tension on the anastomotic site. After the second operation on the trachea a stenosis of the anastomotic site occurred. However, no signs of relapse are evident to date (November 1977).

\section{CASE 5}

A 55-year-old woman underwent subtotal thyroidectomy in 1947 for thyroid carcinoma. She was operated on again in 1958 because of a recurrence. Radiotherapy was also given. She suffered an attack of dyspnoea in 1969 and was admitted to hospital for urgent tracheostomy. The chest radiograph showed a shadow on the right of the mediastinum, and blood-stained sputum was observed. No further investigations were performed, however, and the patient was discharged three months later.

In May 1974 dyspnoea and haemoptysis recurred. After a tracheostomy at another hospital the patient was transferred to our hospital. On admission, a hard tumour the size of a walnut was palpated in the right anterocervical region. The chest radiograph (Fig. 3) showed a large tumour in the right superior mediastinum. When the tracheal lumen was observed through a flexible bronchoscope inserted from the tracheal stoma the lumen was noted to be remarkably narrowed by the tumour immediately above the carina. The tomogram showed that the narrowing began about $2 \mathrm{~cm}$ above the carina, and the right main bronchus was almost completely obstructed (Fig. 4). Phlebography of the superior vena cava showed

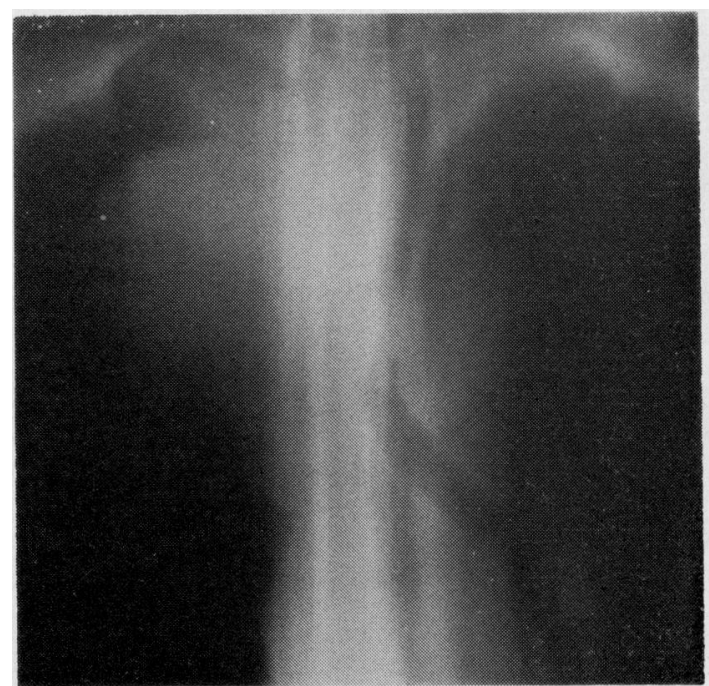

Fig. 4 Tomogram of case 5. Narrowing begins about $2 \mathrm{~cm}$ above carina, and the tumour obstructs right main bronchus almost completely. 


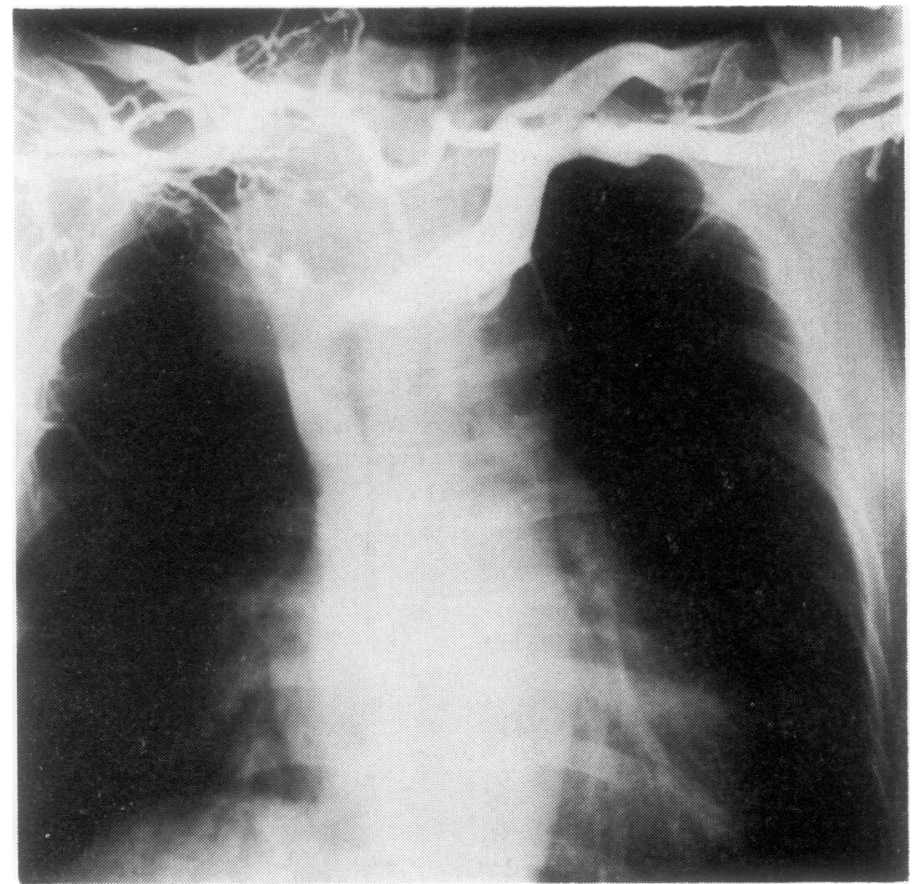

Fig. 5 Venogram of case 5. Right brachiocephalic vein is obstructed completely by tumour.

complete obstruction of the right brachiocephalic vein (Fig. 5). Radical resection seemed difficult, but since the patient had large amounts (200-300 $\mathrm{ml}$ ) of haemoptysis daily and was often attacked by crises of suffocation, we decided to operate in two stages.

The first operation, aimed at stopping haemoptysis and relieving dyspnoea, was performed via a right thoracotomy. There was a large tumour in the right thoracic cavity extending from the paratracheal region to the hilum and surrounding the lower trachea and the carina. Right pneumonectomy was performed, thus allowing the resection of the lower trachea (four rings) and the carina together with most of the thyroid carcinoma in the thoracic cavity. End-to-end anastomosis of the trachea and left main bronchus was performed, but some tumour was left around the anastomotic site. A tracheal tube was inserted from the tracheostome through the anastomotic site in the trachea as a stent. The patient removed this tube the next morning. On the seventh day the anastomotic site finally disrupted, and the patient died.

CASE 6

A 46-year-old woman was operated on in 1950 and in 1959 for malignant goitre, but the details are unknown. Blood-stained sputum was noted in October 1974. Hoarseness suddenly appeared in
March 1975. She was examined at the Ito Hospital $\stackrel{\mathbb{\Omega}}{\rightarrow}$ in June 1975 when tracheal infiltration by thyroid윽 carcinoma was suspected, and she was admitted to Keio University Hospital. On bronchoscopy, a记 tumour was seen bulging from the right side of the trachea into the lumen (Fig. 6). Operation was

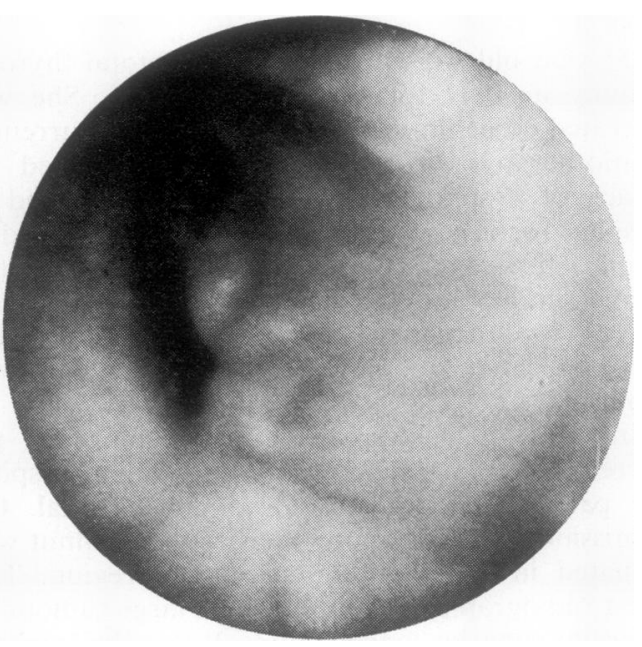

Fig. 6 Bronchoscopic view of case 6. A bulging tumour is evident on right side of tracheal wall. 
performed on 9 July 1975. The tumour was the size of a walnut, infiltrating the right wall of the trachea. Sleeve resection of six tracheal rings from the second to the seventh was performed, and the trachea was reconstructed by end-to-end anastomosis.

Although a tumour was also observed in the left lobe of the thyroid gland, biopsy during operation showed chronic thyroiditis only; therefore it was not excised. Nevertheless, one year and five months after operation the left goitre grew, and malignant goitre was diagnosed. The tumour on the left side of the trachea was excised in January 1977. The microscopic diagnosis was papillary adenocarcinoma similar to the tumour on the right side. The subsequent course has been satisfactory.

\section{CASE 8}

This 49-year-old man noticed blood in his sputum in March 1975 but neglected it. He was admitted to Keio University Hospital on 16 October 1975. The chest radiograph showed many nodular shadows in both lungs, closely resembling pulmonary metastases arising from thyroid carcinoma. The thyroid gland was therefore investigated by scintigraphy (Fig. 7). There appeared to be a defect in the right lower pole. Careful palpation of the neck then disclosed a tumour in the suprasternal notch. Because tracheal infiltration by thyroid carcinoma was suspected, bronchoscopy was performed on 28 October. A tumour bulging from the right wall of the trachea into the lumen was confirmed. On 12 November an operation was performed via a median sternotomy and a right-sided collar incision. The tumour occupied the entire right lobe of the thyroid gland, surrounding the right common carotid, innominate, and right subclavian arteries. It was difficult to isolate these arteries from the tumour. The trachea was also invaded extensively. Firstly, 10 tracheal rings from the second to the eleventh were resected, followed by reconstruction by endto-end anastomosis. Then, the innominate, right common carotid, right subclavian and right vertebral arteries, and the right internal jugular vein were ligated and severed proximal and distal to the tumour, which was excised together with these vessels. A woven Teflon prosthetic graft was then inserted between the innominate and right common carotid arteries.

When the endotracheal tube was removed after completion of the operation, signs of tracheal obstruction occurred, necessitating reintubation. Although removal of the tube was attempted several times, obstruction recurred. The patient returned to the ward with the endotracheal tube in place. Although the airway was secured by intubation,

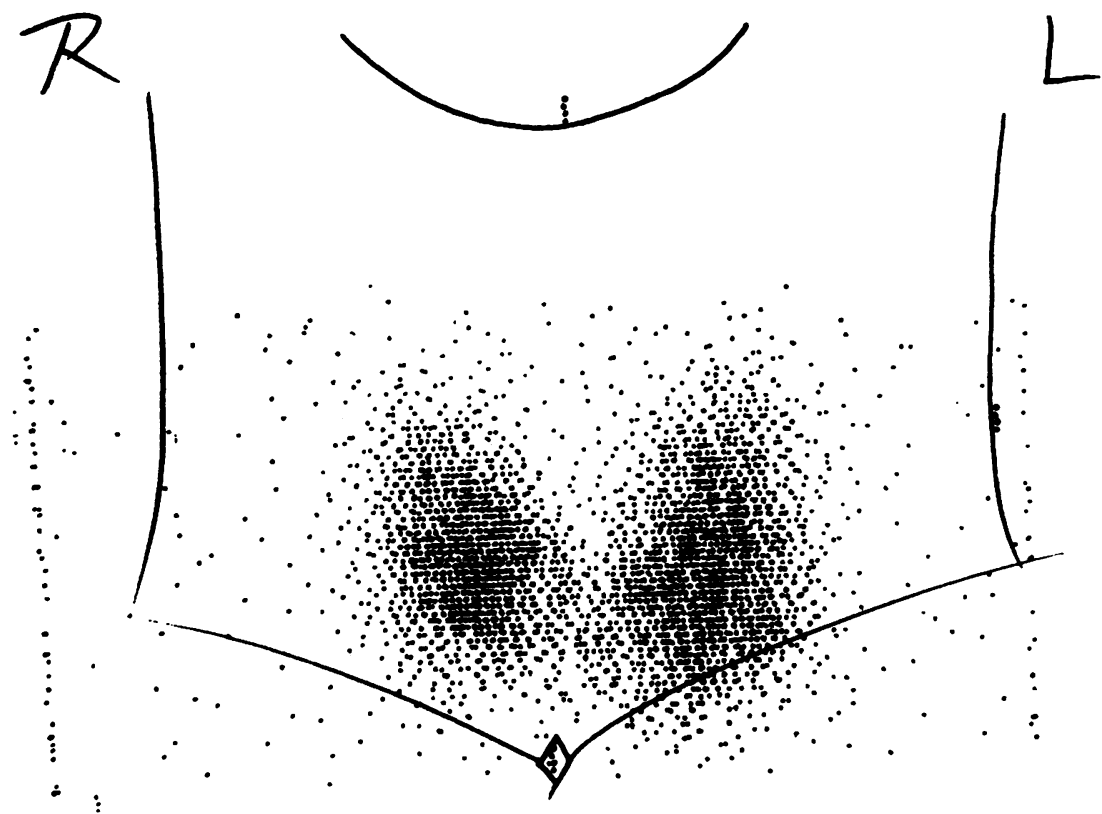

Fig. 7 Scintigram of thyroid of case 8. There appears to be a defect in right lower pole. 


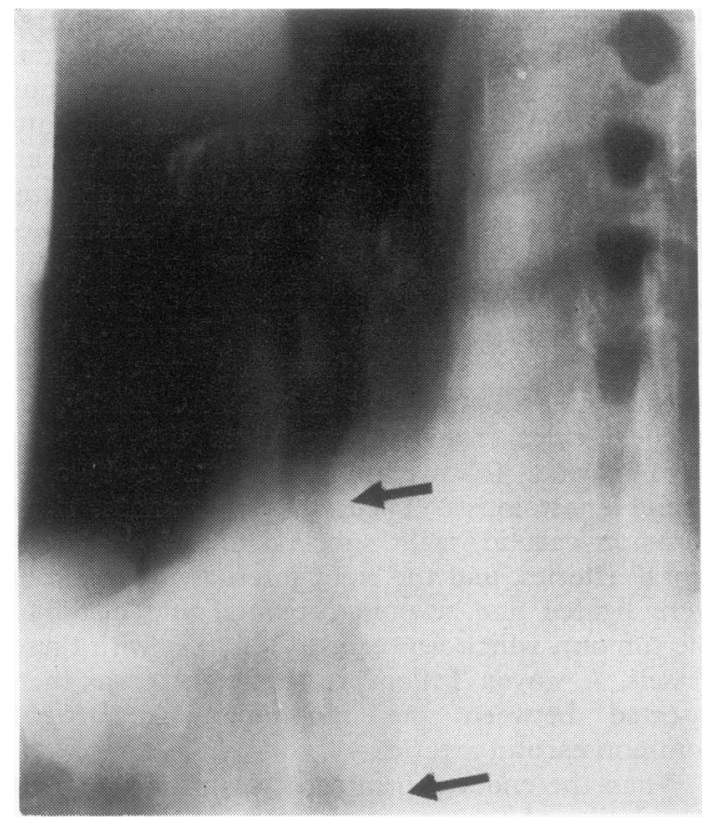

Fig. 8 Oblique tomogram of trachea in case 11. Trachea is noticeably stenotic between upper and lower arrows. Tracheal lumen of this patient was completely obstructed when neck was gently compressed.

saliva flowed into the trachea alongside the tracheal tube, necessitating frequent aspirations of the trachea. We thought it inadvisable to inflate the cuff of the endotracheal tube, even though it was a low-pressure type, because of the tension on the suture line. Tracheostomy could not be performed because of the adjacent prosthetic arterial graft. Finally, a small window was opened in the trachea, and the skin was sutured to it so as to secure an airway. Although the site of tracheal fenestration and the surrounding tissues were sutured in two layers to prevent contamination of the prosthetic graft, infection could not be prevented.

On 22 November about $400 \mathrm{ml}$ of blood flowed from the tracheal window. The patient was immediately taken to the theatre where the wound in the neck was opened to remove the prosthetic graft. The right common carotid artery was ligated, but the innominate artery could not be ligated. We were compelled to suture its aortic origin. After this operation the central nervous system remained intact. After about 12 weeks, despite intensive antibiotic treatment, the upper part of the sternum began to bulge. Aortography performed on 18 February 1976 showed a false aneurysm in the upper part of the aortic arch. We operated again $\underset{\Rightarrow}{\stackrel{B}{\rightarrow}}$ on 23 February. To isolate the contaminated area the approach was via a bilateral transverse thoracotomy at the level of the fourth interspace. Under extracorporeal circulation the anterior wall of the $\mathbb{D}$ aorta was incised, and a woven Teflon patch was sutured to the neck of the aneurysm from inside $\$$ the aorta. The recovery of the patient was un- $\overrightarrow{0}$ eventful, and he was able to walk around the $\vec{\exists}$ ward. On 17 March 1976, however, massive $\stackrel{\omega}{\circ}$ haemorrhage suddenly occurred from the tracheal window, and the patient died.

CASE 10

A 47-year-old woman noticed a goitre in 1970 but neglected it. Thyroid carcinoma was diagnosed at 0 the Ito Hospital in February 1975, and thyroidectomy was performed. Some carcinoma remained on the tracheal wall. Antitumour chemotherapy was given, but a tumour appeared in the neck in May 1976. Haemoptysis started in September. $\vec{\theta}$ Operation was performed on 8 December 1976. A tumour the size of a large walnut was situated in the front of the trachea, infiltrating the right tracheal wall at the cricoid cartilage and penetrating into the lumen through the first, second, and third tracheal rings. The anterior half of the $\stackrel{\mathbb{D}}{\perp}$ cricoid cartilage and the first to fifth tracheal rings $\stackrel{2}{\vec{\prime}}$ were resected in tubular form together with the $\frac{3}{3}$ tumour, and the trachea was reconstructed by end- $\frac{}{2}$ to-end anastomosis. Part of the oesophageal wall was also resected. Although the histological diagnosis was papillary adenocarcinoma, there were also areas of follicular and medullary structure. Because of postoperative laryngeal stenosis, tra- $\dot{\sigma}$ cheal fenestration was performed. The patient was 3 discharged on 9 February 1977. Later, a tumour appeared below the jaw on the right side and gradually enlarged. The patient was admitted on $\mathrm{O}$ 26 May 1977 for resection of this tumour. She was discharged on 18 June but was admitted for the third time on 22 August 1977 because of violent headaches. A brain scan showed one tumour o shadow in a frontal lobe, one in a parietal lobe, $N$ and one in the cerebellum. She suddenly became N unconscious on 1 September and died.

At necropsy, there were masses of metastasised lymph nodes in the paratracheal region extending from the neck into the mediastinum, and dis- $\stackrel{\infty}{\oplus}$ seminated tumour was observed on both pleurae. Several metastatic foci smaller than $1 \mathrm{~cm}$ were 0 noted in the parenchyma of both lungs. There $\overrightarrow{\mathbb{D}}$ was also a tumour $1.5 \mathrm{~cm}$ in diameter in the head $\frac{\rho}{\mathbb{O}}$ of the pancreas. The cause of death was haemor- $\frac{\varrho}{2}$ rhage from a metastatic focus in the cerebellum. No tumour was found in the trachea. 
CASE 11

This 63-year-old woman underwent radical neck dissection for thyroid carcinoma at a university hospital in January 1976. There was recurrence in August 1976 and a second operation was performed. She was still in poor condition after the operation. Blood-stained sputum appeared from December 1976. In February 1977 dyspnoea appeared and gradually became pronounced. She was admitted to Keio University Hospital on 4 March 1977. On admission the trachea was so narrowed that the slightest pressure on the neck in the course of palpation caused tracheal obstruction. On 23 March 1977 operation was performed under partial extracorporeal circulation. Ten tracheal rings including part of the cricoid cartilage were resected, the trachea was reconstructed by end-to-end anastomosis, and a laryngeal release was performed. Because of postoperative laryngeal stenosis, tracheal fenestration was carried out. The laryngeal stenosis was gradually relieved, and the tracheal window has almost closed. Recently, the patient developed pain in the right arm suggestive of a cervical vertebral metastasis.

\section{Results}

Three of the 11 patients died. Two patients (cases 5,8 ) died from the surgery, and one (case 10) died from distant metastases.

In one patient (case 2 ), thyroid carcinoma recurred in the tracheal wall three years and five months after resection. A second resection of the trachea was done, after which stenosis of the anastomotic site occurred from partial separation of the divided ends.

In three patients (cases $9,10,11$ ) in whom the operation extended to the subglottic space, laryngeal stenosis occurred later.

In one patient (case 6) in whom thyroid carcinoma recurred on the opposite side the trachea was not invaded. In another patient (case 11) metastasis of thyroid carcinoma to the cervical vertebrae became obvious after operation.

Five patients (cases 1, 3, 4, 6, 7) are well with no signs of relapse two years and one month to four years and seven months after the operation.

\section{Discussion}

The prognosis after treatment is better in thyroid carcinoma than in most other carcinomas. However, when a progressive tumour has infiltrated into the surrounding tissues, especially the trachea, the tracheal lumen is narrowed, leading to obstruction and often to fatal haemorrhage.
All 11 patients in this series complained of blood-stained sputum. Five of them had dyspnoea. When blood-stained sputum is observed after treatment of a thyroid carcinoma, endoscopic examination should be performed (Ishihara et al., 1976). Blood-stained sputum is a common symptom, but the possibility of thyroid carcinoma should also be considered when diagnosing patients who have this as a primary symptom.

In some patients with tracheal infiltration by thyroid carcinoma the tumour extends to the cricoid cartilage. When the cricoid cartilage is partly resected the larynx loses its support and is narrowed. In this series we have resected the anterior half of the cricoid cartilage in three patients. Pearson et al. (1975) reported a method by which the cricoid cartilage is resected while maintaining the integrity of the recurrent nerves. In our three patients, however, laryngeal stenosis occurred after the operation. In one of these an airway was secured by tracheostomy, and in the other two by tracheal fenestration, using a simplified form of the method of Rockey (1957). We have often performed tracheal fenestration for laryngeal stenosis caused by operations on the cervical trachea. This tracheal fenestration has some advantages. In patients in whom a long length of the trachea is resected and the trachea is reconstructed by end-to-end anastomosis the tracheal wall is under excessive tension. In such patients, when a tube is inserted into the trachea, damage to the tracheal wall occurs earlier and is more severe than usual. Our tracheal fenestration, however, in which a window is opened in the anterior wall of the trachea and the surrounding skin is sutured to the margin of the window, does not result in damage to the tracheal wall when a tube is inserted. Even though a window is opened, it is possible to use the voice and no inconvenience arises. When the need for a window has passed, it can be simply closed.

End-to-end anastomosis is recommended for reconstructing the trachea after resection, even when a long length is resected (Grillo et al., 1964; Naef, 1969). In two of our 11 patients, after 10 rings of the trachea had been resected, the trachea was reconstructed by end-to-end anastomosis, and the suture line remained intact. In two other patients the laryngeal release of Dedo and Fishman (1969) was performed. This method is useful in patients in whom the anastomotic site is under great tension.

In case 8 the surgical treatment of both trachea and blood vessels was performed simultaneously. This seemed to decide the postoperative prognosis of the patient. If the tumour had been divided into 
two along its centre and only the half of the tumour affecting the trachea had been resected, while leaving the other half affecting the blood vessels, this patient might have survived. However, we do not know whether after partial resection of a thyroid carcinoma the remaining tumour will proliferate rapidly or remain relatively static thus allowing a subsequent attempt at excision.

In thyroid carcinoma a tumour that grows slowly may suddenly proliferate (case 5); or a tumour may proliferate comparatively early (cases 10 and 11). Even adenocarcinoma, which is well differentiated, may change to an anaplastic type (Harada et al., 1977). In case 10, although the trachea was reconstructed satisfactorily, the patient's life was not prolonged. Case 11, although the tracheal stenosis was relieved dramatically, now has a metastasis in a cervical vertebra. As with other carcinoma, metastasis may occur, although local resection is complete.

We used partial extracorporeal circulation for 32 minutes during the operation in case 11 . In this patient endotracheal anaesthesia was impossible because of severe tracheal stenosis. The operation was performed safely using extracorporeal circulation. Nevertheless, after operation there was prolonged haemorrhage from the wound, and healing was delayed.

\section{References}

Dedo, H. H., and Fishman, N. H. (1969). Laryngeal release and sleeve resection for tracheal stenosis.
Annals of Otology, Rhinology, and Laryngology, 78 285-296.

Grillo, H. C., Dignan, E. F., and Miura, T. (1964)당 Extensive resection and reconstruction of medias tinal trachea without prosthesis or graft: an anatomical study in man. Journal of Thoracic an Cardiovascular Surgery, 48, 741-749.

Harada, T., Ito, K., Shimaoka, K., Hosoda, Y., and. Yakumaru, K. (1977). Fatal thyroid carcinoma? Anaplastic transformation of adenocarcinoma Cancer, 39, 2588-2596.

Ishihara, T., Kikuchi, K., Ikeda, T., Murakami, M and Kobayashi, K. (1976). Treatment of thyroie carcinoma infiltrating the tracheal wall. Operation 30, 195-200 (in Japanese).

Naef, A. P. (1969). Extensive tracheal resection and tracheobronchial reconstruction. Annals of Thoraciob Surgery, 8, 391-401.

Pearson, F. G., Cooper, J. D., Nelems, J. M., and vañ Nostrand, A. W. P. (1975). Primary tracheal anase tomosis after resection of the cricoid cartilage witt preservation of recurrent laryngeal nerves. Journd $\vec{P}$ of Thoracic and Cardiovascular Surgery, 70, 806-816.6

Rockey, E. E. (1957). Surgical technic of tracheaț fenestration. American Journal of Surgery, 94, 486:489.

Requests for reprints to: T. Ishihara, MD, Depart? ment of Surgery, School of Medicine, Keio University Shinanomachi, Shinjuku-ku, Tokyo 160, Japan. 